\title{
Laparoscopic adrenalectomy for pheochromocytoma is more difficult compared to other adrenal tumors
}

\author{
Michat Natkaniec ${ }^{1}$, Michat Pędziwiatr ${ }^{1}$, Mateusz Wierdak ${ }^{1,2}$, Magdalena Białas ${ }^{3}$, Piotr Major ${ }^{1}$, Maciej Matłok ${ }^{1}$, \\ Piotr Budzyński ${ }^{1}$, Jadwiga Dworak ${ }^{1}$, Monika Buziak-Bereza ${ }^{4}$, Andrzej Budzyński ${ }^{1}$ \\ ${ }^{1} 2^{\text {nd }}$ Department of General Surgery, Jagiellonian University Medical College, Krakow, Poland \\ ${ }^{2}$ Department of Physiology, Jagiellonian University Medical College, Krakow, Poland \\ ${ }^{3}$ Department of Pathomorphology, Jagiellonian University Medical College, Krakow, Poland \\ ${ }^{4}$ Department of Endocrinology, Jagiellonian University Medical College, Krakow, Poland
}

Videosurgery Miniinv 2015; 10 (3): 466-471 DOI: $10.5114 /$ wiitm.2015.52869

\begin{abstract}
Introduction: Laparoscopic adrenalectomy is the gold standard for the treatment of benign adrenal tumors. However, some authors raise the problem of differences in surgery for pheochromocytoma in comparison to other lesions.

Aim: To compare laparoscopic adrenalectomy for pheochromocytoma and for other tumors.

Material and methods: Four hundred and thirty-seven patients with adrenal tumors were included in the retrospective analysis. Patients were divided into two groups: 1 (124 patients treated for pheochromocytoma) and 2 (313 patients with other types of tumor). The two groups were compared with respect to mean operative time, intraoperative blood loss, conversion rate, complication rate and the relationship of tumor size with operative time. Results: The mean operative time in group 1 was $91 \mathrm{~min}$, and in group 2 it was $82 \mathrm{~min}(p=0.016)$. In both groups 1 and 2, tumor size correlated with operative time ( $<<0.0001$ and $p=0.0003$, respectively). The mean blood loss in groups 1 and 2 was $117 \mathrm{ml}$ and $54 \mathrm{ml}$, respectively $(p=0.0011)$. The complication rate in groups 1 and 2 was $4 \%$ and $4.2 \%$, respectively $(p=0.9542)$. In groups 1 and 2, conversion was necessary in $2(1.6 \%)$ and $5(1.6 \%)$ cases, respectively $(p=0.9925)$.

Conclusions: Longer operative time and higher blood loss after laparoscopic adrenalectomy for pheochromocytoma indicate its greater difficulty. However, despite these drawbacks, minimally invasive surgery still seems to be an effective and safe method.
\end{abstract}

Key words: safety, laparoscopic surgery, pheochromocytoma, adrenal tumor.

\section{Introduction}

Since Roux and Mayo, who were the first to remove the adrenal gland eighty years ago, adrenalectomy has changed significantly [1]. Pioneers in adrenal surgery did not know the pathophysiology of the glands they operated on. This translated into a relatively high mortality rate [1]. As time went by, the approach changed in terms of preparation for surgery, perioperative care and, obviously, surgical technique [1-3]. Currently, the gold standard is laparoscopic adrenalectomy in cases of benign adrenal tumors [4, 5]. Improved access to the surgical area, less surgical trauma, less pain, fewer complications, shorter length of hospital stay and faster recovery, are all wel-established advantages of laparoscopy [6-8].

Pheochromocytomas, in $80-85 \%$ of cases derived from the chromaffin cells of the medulla, are the sec- 
Table I. Characteristics of groups 1 and 2

\begin{tabular}{|c|c|c|c|c|}
\hline \multicolumn{2}{|c|}{ Parameter } & $\begin{array}{c}\text { Group } 1 \\
124\end{array}$ & $\begin{array}{c}\text { Group } 2 \\
313\end{array}$ & Value of $p$ \\
\hline \multirow[t]{2}{*}{ Gender } & Female & $69(55.6 \%)$ & 219 (70\%) & 0.0044 \\
\hline & Male & 55 (44.4\%) & $94(30 \%)$ & \\
\hline \multirow[t]{2}{*}{ Side } & Left & $54(43.5 \%)$ & 169 (54\%) & 0.0489 \\
\hline & Right & 70 (56.5\%) & $144(46 \%)$ & \\
\hline \multicolumn{2}{|c|}{ Average age } & $53.3 \pm 14.3$ & $55.0 \pm 13.2$ & 0.8324 \\
\hline
\end{tabular}

ond most common adrenal catecholamine-secreting tumors. The hormones they produce cause arterial hypertension and symptoms of paroxysmal stimulation of the adrenergic system [9].

Despite the proven benefits of laparoscopy, some surgeons point to the issue of different surgery for pheochromocytoma, due to its pathophysiology [1, 2, 10, 11]. Creating a pneumoperitoneum and manipulating the tumor during surgery is believed to cause an excessive release of catecholamines, which may increase the risk of bleeding and conversion [12, 13].

The available literature documents many comparisons between adrenalectomy for pheochromocytoma and procedures performed for other reasons $[2,11,13,14]$. The comparative material includes a relatively small number of cases of pheochromocytoma. To the best of our knowledge, this publication is the first comparison of laparoscopic adrenalectomy for pheochromocytoma with laparoscopic adrenalectomy for other adrenal tumors, performed on such a large number of patients.

\section{Aim}

The aim of the study was to compare laparoscopic adrenalectomy due to pheochromocytoma with laparoscopic adrenalectomy performed for other indications.

\section{Material and methods}

The retrospective analysis covered patients with adrenal tumors operated on in the period 20032013. Patients gave their informed consent to participate in the study. Prior to surgery, each patient had undergone imaging studies (computed tomography $(C T)$ or magnetic resonance imaging (MRI)), and the hormonal activity of the tumor was eval- uated. Pheochromocytoma was diagnosed on the basis of clinical presentation and biochemical tests (metanephrine and catecholamine levels in urine samples). In cases of pheochromocytoma, patients were prepared before the procedure with doxazosin - a selective antagonist of $\alpha_{1}$-adrenergic receptors. The procedure was performed from a laparoscopic lateral transperitoneal approach.

Patients were divided into two groups, based on the nature of the tumor. Group 1 included 124 (69 females, 55 males) patients with pheochromocytoma. In group 2, 313 (219 females, 94 males) patients underwent surgery for other types of tumor (Tables I and II).

The two groups were compared with respect to operative time, intraoperative blood loss, conversion rate and complication rate. Complications were classified using the Clavien-Dindo scale [15].

\section{Statistical analysis}

Normal distribution of continuous variables was tested with the $\chi^{2}$ test. Variables that had a non-normal distribution were compared using the Mann-Whitney $U$ test. To measure the degree of linear dependence between two variables, Pearson's correlation coefficient was used. Categorical variables were compared with the $\chi^{2}$ test. Results were considered statistically significant when the $p$-value was found to be less than 0.05 .

Table II. Indications for surgery in group 2

\begin{tabular}{|lcc|}
\hline Indication & Number & Percent \\
\hline Incidentaloma & 174 & 55.5 \\
\hline Cushing syndrome & 72 & 23 \\
\hline Conn's syndrome & 53 & 17 \\
\hline Metastasis & 14 & 4.5 \\
\hline
\end{tabular}




\section{Results}

The average operative time in group 1 (91 $\pm 21 \mathrm{~min})$ was significantly longer than in group $2(82 \pm 23 \mathrm{~min}$, $p=0.016$, Figure 1).

In group 1 , the average size of the adrenal gland was $4.2 \mathrm{~cm}$ (range: $1.5-12 \mathrm{~cm}$ ), and in group 2 it was $4.2 \mathrm{~cm}$ (range: $0.9-16 \mathrm{~cm}$ ). In both groups, tumor size correlated with operative time $(p<0.0001$ and $p=0.0003$, respectively).

The average blood loss in group 1 was $117 \mathrm{ml}$, whereas in group 2 it was smaller and was $54 \mathrm{ml}$. This difference is statistically significant $(p=0.0011$, Figure 2).

In $4(3.2 \%)$ cases in group 1 , blood transfusion was required. In group 2 such a necessity occurred in $7(2.2 \%)$ cases $(p<0.0001)$.

In group 1, conversion occurred in 2 cases, with 5 cases in group $2(p=0.9925)$. The reasons for conversion in both groups are shown in Table III.

In group 1, complications occurred in 5 (4\%) cases. According to the Clavien-Dindo classification, three cases were classified as grade I, and two as grade IIIB. In group 2, 13 cases experienced complications (4.2\%). According to the Clavien-Dindo classification, five complications were grade I, one grade II, and seven grade IIIB. The characteristics of complications are shown in Table IV. The rate of complications was higher in group 2, but this difference did not reach statistical significance $(p=0.9542)$. One patient from group 1 died on the $4^{\text {th }}$ postoperative day due to cardiopulmonary failure despite intensive care treatment.

\section{Discussion}

Twenty-two years have passed since the first report on laparoscopic adrenalectomy was published [16]. Nowadays, minimally invasive surgery in cases of benign adrenal tumors has become a safe method that gives good results $[6-8,17,18]$. However, there is a continuous discussion concerning cases of pheochromocytoma, which can be a challenge to both the surgeon and the anesthetist. Pheochromocytoma

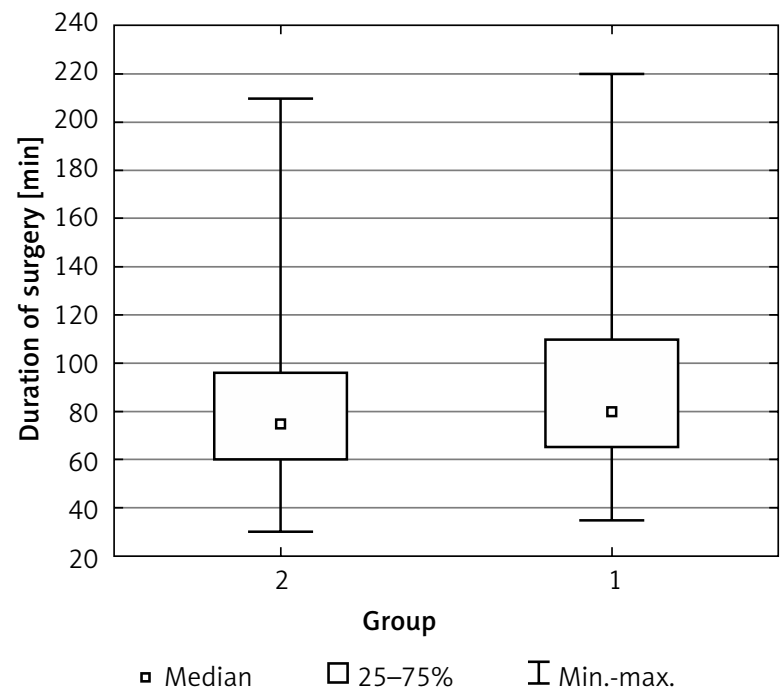

Figure 1. Difference in operative time between groups 1 and 2

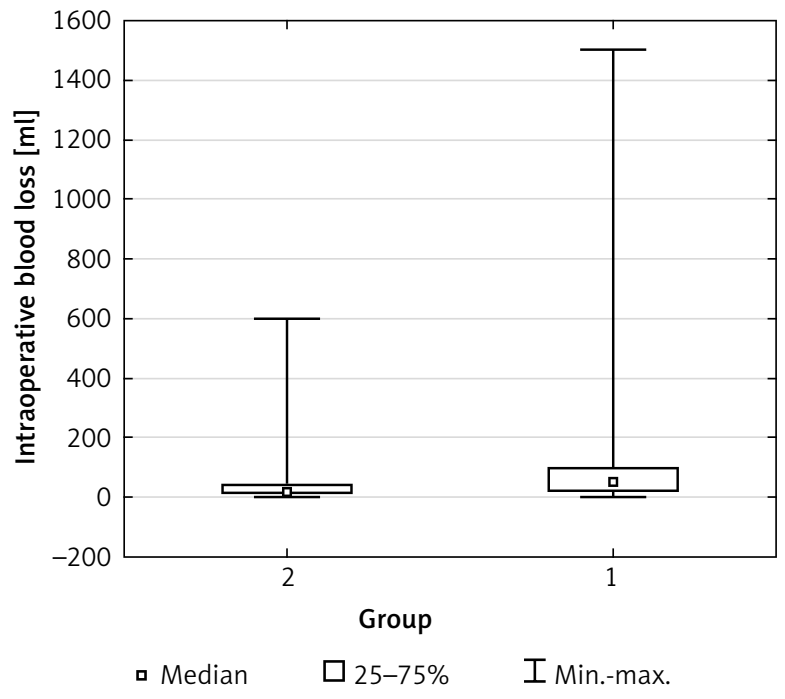

Figure 2. Intraoperative blood loss in groups 1 and 2

Table III. Reasons for conversion in both groups

\begin{tabular}{|ll|}
\hline \multicolumn{1}{|c|}{ Group 1 } & \multicolumn{1}{c|}{ Group 2 } \\
\hline - Unusual location of the tumor & - Conversion due to firm adhesion to surrounding organs \\
- Intraoperative bleeding & - Adhesions after previous laparotomy \\
& Doubts as to the RO resection of laparoscopic surgery - \\
& in 2 cases \\
& Vascular infiltration of adrenal vessels \\
\hline
\end{tabular}


Table IV. Characteristics of complications

\begin{tabular}{|c|c|c|c|c|}
\hline Complications & Group 1 & $\begin{array}{l}\text { According to } \\
\text { Clavien-Dindo } \\
\text { scale }\end{array}$ & Group 2 & $\begin{array}{l}\text { According to } \\
\text { Clavien-Dindo } \\
\text { scale }\end{array}$ \\
\hline \multirow[t]{3}{*}{ Intraoperative } & \multirow[t]{2}{*}{$\begin{array}{l}\text { Intraoperative damage } \\
\text { to the splenic vein } \\
\text { (repaired during laparoscopy) }\end{array}$} & \multirow[t]{2}{*}{ IIIB } & $\begin{array}{c}\text { Diaphragm injury following } \\
\text { pneumothorax (repaired during } \\
\text { laparoscopy) }\end{array}$ & IIIB \\
\hline & & & $\begin{array}{l}\text { Intraoperative damage to the } \\
\text { spleen in } 2 \text { cases }\end{array}$ & $\| \mathrm{II}$ \\
\hline & $\begin{array}{l}\text { Intraoperative damage to } \\
\text { the spleen }\end{array}$ & IIIB & $\begin{array}{l}\text { V. cava injury (repaired during } \\
\text { laparoscopy) in } 2 \text { cases }\end{array}$ & $\| \mathrm{IIB}$ \\
\hline \multirow[t]{4}{*}{ Post-operative } & \multirow[t]{2}{*}{ Wound infection in 2 cases } & \multirow[t]{2}{*}{ । } & Wound infection in 4 cases & I \\
\hline & & & Pulmonary embolism & $\|$ \\
\hline & \multirow{2}{*}{$\begin{array}{l}\text { Subcapsular hematoma of the } \\
\text { liver }\end{array}$} & \multirow[t]{2}{*}{ । } & Right pleural effusion & I \\
\hline & & & $\begin{array}{c}\text { Reoperated due to bleeding in two } \\
\text { cases }\end{array}$ & IIIB \\
\hline
\end{tabular}

was initially considered a contraindication for laparoscopic adrenalectomy $[2,12]$. Over time, the imaging methods have improved, as well as perioperative care, anesthesia, and pharmacological preparation. Thanks to this, the indications for laparoscopic adrenalectomy were gradually extended [19-24].

The specificity of the surgical treatment of pheochromocytoma poses a challenge to perioperative care. It is extremely important to properly prepare the patient before surgery with $\alpha$ - and $\beta$-blockers and intravenous volume expansion with crystalloids. The available literature since the end of the last century provides data on a $17-26 \%$ mortality rate in patients operated on for pheochromocytoma [25, 26]. With the appropriate preoperative management in the pre-laparoscopy era, surgical removal of pheochromocytoma has become a safe procedure. At present, the mortality rate is minimal: approximately $1 \%$ of procedures [27]. The improvement observed in the last two decades was possible thanks to the accurate preoperative localization of the tumor with imaging technology, preoperative management, safe anesthesia, post-operative care and, above all, improved surgical technique [1-3].

It was reported that the operative time of laparoscopic adrenalectomy for pheochromocytoma is longer in comparison to other lesions [2, 5, 11 , $28,29]$. In our study, we also observed a statistically significant difference between the compared groups. This can be explained by caution and delicacy during dissection of the tumor due to concern about uncontrolled secretion of catecholamines and the risk of intraoperative bleeding. This aspect supports the claim that adrenalectomy due to pheochromocytoma is indeed more complicated. It was also observed that the operative time in both groups correlated with the size of the tumor. Similar results were presented by Kercher et al. [5]. It appears that the size of the tumor, despite its histological type, determines the time of surgery to a greater extent, and thereby - indirectly - its difficulty. Literature available on the subject provides us with reports on laparoscopic procedures performed safely in cases of large tumors [4, 21, 30]. In our study, we observed 16 pheochromocytoma cases with a diameter greater than $6 \mathrm{~cm}$. There were two conversions in this group. The reason for one of them was bleeding, which was difficult to control laparoscopically (a large tumor with a diameter of $12 \mathrm{~cm}$ ); in the second case, the decision to convert was made due to hemodynamic instability and abnormal location of the tumor (a tumor with a diameter of $6.7 \mathrm{~cm}$ ). The remaining $14 \mathrm{tu}$ mors were successfully removed laparoscopically. It seems that laparoscopic adrenalectomy of large pheochromocytoma is safe as long as the surgeon has the appropriate experience. This conclusion is consistent with the findings of other authors [4, 10, 29]. The average blood loss was significantly higher in group 1. Greater intraoperative bleeding in the case of pheochromocytoma could be explained by a more prominent network of vessels with higher pressure, due to the elevated levels of catecholamines [2]. Four (3.2\%) cases in group 1 required 
blood transfusions. In group 2, this necessity occurred in $7(2.2 \%)$ cases $(p<0.0001)$. This difference supports the hypothesis of greater difficulty in the treatment of pheochromocytoma.

In our study, the complication rate was $4 \%$ and $4.2 \%$ in groups 1 and 2 , respectively $(p=0.9542)$; these rates are comparable to the material of Toniato et al. [14] and lower than those reported by other authors [1, 2, 31, 32]. The difference in conversion rate between the two groups is not statistically significant. The conversion rate in both groups was $1.6 \%$, which is also comparable with other authors $[1,3,33]$. On the basis of these data, one can draw the conclusion that the histological type of tumor has no significant impact on the incidence of complications and conversions, and adrenalectomies performed due to pheochromocytoma as well in other tumors are equally safe despite the greater technical difficulty of the former.

Some surgeons raise the issue of operative technique. Originally it was believed that the pressure of pneumoperitoneum could result in a significant release of catecholamines [25]. Further studies, however, did not confirm this hypothesis. Inabet et al. compared hemodynamic parameters during laparoscopic and open adrenalectomy [34]. The authors demonstrated that, despite the observed increased blood pressure, central venous pressure, and the pressure in the pulmonary capillary wedge, the creation of pneumoperitoneum does not alter the heart rate significantly. Another question concerning operative technique concerns the approach. Myśliwiec et al. [35] compared adrenalectomy (including adrenalectomy for pheochromocytoma) by the lateral transperitoneal approach and the posterior retroperitoneal approach. They found that both mentioned approaches are safe and efficient.

\section{Conclusions}

Based on the data presented above, we conclude that laparoscopic surgery for pheochromocytoma is more difficult. However, the difference in difficulty has no influence on the clinical outcomes, compared to the other lesions. It remains a safe procedure when performed in centers with sufficient experience.

\section{Conflict of interest}

The authors declare no conflict of interest.

\section{Acknowledgments}

The publication of this paper was supported by the Faculty of Medicine, Jagiellonian University Medical College, Leading National Research Centre (KNOW) 2012-2017.

\section{References}

1. Cheah WK, Clark OH, Horn JK, et al. Laparoscopic adrenalectomy for pheochromocytoma. World J Surg 2002; 26: 1048-51.

2. Kalady MF, McKinlay R, Olson JA Jr, et al. Laparoscopic adrenalectomy for pheochromocytoma. A comparison to aldosteronoma and incidentaloma. Surg Endosc 2004; 18: 621-5.

3. Conzo G, Pasquali D, Della Pietra C, et al. Laparoscopic adrenal surgery: ten-year experience in a single institution. BMC Sugery 2013; 13 Suppl 2: S5.

4. Walz MK, Petersenn S, Koch JA, et al. Endoscopic treatment of large primary adrenal tumours. Br J Surg 2005; 92: 719-23.

5. Kercher KW, Novitsky YW, Park A, et al. Laparoscopic curative resection of pheochromocytomas. Ann Surg 2005; 241: 919-29.

6. Smith CD, Weber CJ, Amerson JR. Laparoscopic adrenalectomy: new gold standard. World J Surg 1999; 23: 389-96.

7. Jacobs JK, Goldstein RE, Geer RJ. Laparoscopic adrenalectomy: a new standard of care. Ann Surg 1997; 225: 495-502.

8. Gagner M. Laparoscopic adrenalectomy. Surg Clin North Am 1996; 76: 523-37.

9. Lenders JW, Eisenhofer G, Mannelli M, et al. Phaeochromocytoma. Lancet 2005; 366: 665-75.

10. Joris JL, Hamoir EE, Hartstein GM, et al. Haemodynamic changes and catecholamine release during laparoscopic adrenalectomy for pheochromocytoma. Anesth Analg 1999; 88: 16-21.

11. Mellon MJ, Sundaram ChP. Laparoscopic adrenalectomy for pheochromocytoma versus other surgical indications. JSLS 2008; 12: 380-4.

12. Brunt LM, Lairmore TC, Doherty GM, et al. Adrenalectomy for familial pheochromocytoma in the laparoscopic era. Ann Surg 2002; 235: 713-20.

13. Henry JF, Sebag F, lacobone M, et al. Results of laparoscopic adrenalectomy for large and potentially malignant tumors. World J Surg 2002; 26: 1043-7.

14. Toniato A, Boschin I, Bernante P, et al. Laparoscopic adrenalectomy for pheochromocytoma: is it really more difficult? Surg Endosc 2007; 21: 1323-6.

15. Dindo D, Demartines N, Clavien PA. Classification of surgical complications. A new proposal with evaluation in a cohort of 6336 patients and results of a survey. Ann Surg 2004; 240: 205-13.

16. Gagner M, Lacroix A, Bolte E. Laparoscopic adrenalectomy in Cushing's syndrome and pheochromocytoma. N Engl J Med 1992; 327: 1033

17. Hora M, Ürge T, Stránský P. Laparoendoscopic single-site surgery adrenalectomy - own experience and matched case-control study with standard laparoscopic adrenalectomy. Videosurgery Miniinv 2014; 9: 596-602.

18. Murphy MM, Witkowski ER, Ng SC, et al. Trends in adrenalectomy: a recent national review. Surg Endosc 2010; 24: 2518-26. 
19. Heniford BT, Arca MJ, Walsh RM, et al. Laparoscopic adrenalectomy for cancer. Semin Surg Oncol 1999; 16: 293-306.

20. Kebebew E, Siperstein AE, Clark OH, et al. Results of laparoscopic adrenalectomy for suspected and unsuspected malignant adrenal neoplasms. Arch Surg 2002; 137: 948-51.

21. Novitsky YW, Czerniach DR, Kercher KW, et al. Feasibility of laparoscopic adrenalectomy for large adrenal masses. Surg Laparosc Endosc Percutan Tech 2003; 13: 106-10.

22. Hasan R, Harold KL, Matthews BD, et al. Outcomes for laparoscopic bilateral adrenalectomy. J Laparoendosc Adv Surg Tech A 2002; 12: 233-6.

23. Imai T, Kikumori T, Shibata A, et al. Laparoscopic adrenalectomy for incidentaloma and bilateral adrenal disease. Asian J Surg 2003; 26: 64-70.

24. Pędziwiatr M, Matłok M, Kulawik J, et. al. Laparoscopic adrenalectomy by the lateral transperitoneal approach in patients with a history of previous abdominal surgery. Videosurgery Miniinv 2013; 8: 146-51.

25. Janetschek G, Finkenstedt G, Gasser R, et al. Laparoscopic surgery for phaeochromocytoma: adrenalectomy, partial resection, excision of paragangliomas. J Urol 1998; 160: 330-4.

26. Mann C, Millat B, Boccara G, et al. Tolerance of laparoscopy for resection of phaeochromocytoma. Br J Anaesth 1996; 77: 795801.

27. Orchard T, Grant CS, van Heerden JA, et al. Pheochromocytoma: continuing evolution of surgical therapy. Surgery 1993; 114: $1153-9$

28. Tiberio GA, Solaini L, Arru L, et al. Factors influencing outcomes in laparoscopic adrenal surgery. Langenbecks Arch Surg 2013; 398: 735-43.

29. Hobart MG, Gill IS, Schweizer D, et al. Laparoscopic adrenalectomy for large-volume (> or $=5 \mathrm{~cm}$ ) adrenal masses. J Endourol 2000; 14: 149-54.

30. Beisa V, Klimovskij M, Simutis G, et al. Two-stage bilateral laparoscopic adrenalectomy for large pheochromocytomas. Videosurgery Miniinv 2014; 9: 110-4.

31. Sprung J, O'Hara JF Jr, Gill IS, et al. Anesthetic aspects of laparoscopic and open adrenalectomy for phaeochromocytoma. Urology 2000; 55: 339-43.

32. Conzo G, Musella M, Corcione F, et al. Laparoscopic adrenalec tomy, a safe procedure for pheochromocytoma. A retrospective review of clinical series. Int J Surg 2013; 11: 152-6.

33. Shen WT, Kebebew E, Clark OH, et al. Reasons for conversion from laparoscopic to open or hand-assisted adrenalectomy: review of 261 laparoscopic adrenalectomies from 1993 to 2003. World J Surg 2004; 28: 1176-9.

34. Inabet WB, Pitre J, Bernard D, et al. Comparison of the hemodynamic parameters of open and laparoscopic adrenalectomy for phaeochromocytoma. World J Surg 2000; 24: 574-8.

35. Myśliwiec P, Marek-Safiejko M, Lukaszewicz J, et al. Videoscopic adrenalectomy - when does retroperitoneal seem better? Videosurgery Miniinv 2014; 9: 226-33.

Received: 23.02.2015, accepted: 6.06.2015. 